\title{
Hard lessons: learning from the Charlie Gard case
}

\author{
Dominic Wilkinson, ${ }^{1,2}$ Julian Savulescu ${ }^{1,3,4}$
}

${ }^{1}$ Faculty of Philosophy, Oxford Uehiro Centre for Practical Ethics, University of Oxford, Oxford, UK

${ }^{2}$ Newborn Care Unit, John Radcliffe Hospital, Oxford, UK ${ }^{3}$ Murdoch Childrens Research Institute (Visiting), Melbourne, Australia

${ }^{4}$ Melbourne Law School (Visiting), Melbourne, Australia

\section{Correspondence to}

Professor Julian Savulescu, Oxford Uehiro Centre for Practical Ethics, Oxford OX1 1PT, UK;

julian.savulescu@philosophy. ox.ac.uk

Received 25 July 2017 Accepted 25 July 2017 Published Online First 2 August 2017
Check for updates

To cite: Wilkinson $D_{\text {, }}$ Savulescu J. J Med Ethics 2018:44:438-442.
On 24 July 2017, the long-running, deeply tragic and emotionally fraught case of Charlie Gard reached its sad conclusion (box 1). Following further medical assessment of the infant, Charlie's parents and doctors finally reached agreement that continuing medical treatment was not in Charlie's best interests. Life support was subsequently withdrawn and Charlie died on 28 July 2017.

Over the course of multiple hearings at different levels of courts in both London and Strasbourg, the Charlie Gard case has raised a number of vexed ethical questions (box 2). The important role of practical ethics in cases like this is to help clarify the key concepts, identify central ethical questions, separate them from questions of scientific fact, and subject arguments to critical scrutiny. The authors have disagreed about the right course of action for Charlie Gard, ${ }^{12}$ but we agree on the key ethical principles as well as the role of ethical analysis and the importance of robust and informed debate. Ethics is not about personal opinion, but about argument, reasons and rational reflection. While the lasting ramifications of the case for medical treatment decisions in children are yet to become apparent, we here outline some of the potential lessons.

\section{PARENTS' ROLE IN DECISION-MAKING FOR CHILDREN: WE NEED TO CLARIFY HARM}

Much of the media attention in the Gard case has focused on the rights of parents in decision-making for children, and whether the intervention of the courts in this case means that doctors frequently overrule parents in the UK. However, cases of intractable disagreement like this are the exception rather than the rule. In the majority of cases in the UK, as elsewhere, ${ }^{3}$ parents and doctors reach decisions together through a process of shared decision-making. However, there have to be limits. Parents should not be allowed to make decisions that carry a significant risk of serious harm to a child. That includes refusing treatments of likely benefit for a child, or demanding treatments that impose a significant burden without benefit. The challenge, of course, and here there needs to be much more work, is in defining what constitutes a sufficient level or chance of harm to justify overruling parents. ${ }^{4}$ Charlie would have had to potentially undergo some months of pain and discomfort from continued intensive care, ${ }^{1}$ however, the doctors at Great Ormond Street Hospital indicated that they felt that his neurological damage was so great that he was'beyond experience'. ${ }^{5}$ If that were truly the case, then it is not clear that acquiescing to parental request for treatment would have actually constituted significant harm (although it would also, almost certainly, mean that treatment would have had no chance at all of securing the improvement they desired). We have both disagreed about whether this harm threshold was reached, and consequently whether Charlie's parents' request should have been granted. ${ }^{12}$

\section{DECISIONS FOR ADULTS VERSUS DECISIONS FOR CHILDREN: ALLOW ADULTS TO CHOOSE TREATMENT FOR THEMSELVES EVEN IF SUBOPTIMAL}

While there has been intense debate about whether or not requested treatment should be provided to Charlie Gard, it is important not to extrapolate from this case to decisions about medical treatment in adults. The ethical and legal basis for decisions in competent (or formerly competent) adults is different from that in children. If Charlie had been a young adult who had made clear his wishes to be kept alive on a ventilator, and to receive experimental treatment (even if there was a low chance of benefiting), then it should certainly have been provided. ${ }^{6}$ For public health systems, it is important to manage fairly the limited healthcare resources we have. However, adult patients should be allowed to access cost-equivalent treatment alternatives, even if they would be inferior to the usually recommended standard of care. ${ }^{7}$

\section{EXPERIMENTAL TREATMENT: WE SHOULD HAVE A LOWER THRESHOLD FOR ALLOWING ACCESS WHERE PATIENTS HAVE NO OTHER OPTIONS, AND ALLOW EARLIER INNOVATIVE TREATMENT}

Faced with certain death without treatment, Charlie's parents sought, and found, an experimental treatment that could conceivably benefit him. This treatment had not been tried in any previous patients with Charlie's illness, and on that basis was rejected as offering no known benefit. However, this suggests a Catch-22: new treatments can only be tried if there is evidence from previous patients, but that evidence can only be acquired by trying it.

Moreover, Charlie was only one of four patients in the world with this condition. Large trials could not be performed and animal models could not be developed in time to help Charlie.

Novel experimental treatments are sometimes tried first in patients with lesser forms of an illness, or in healthy patients. However, that approach is arguably mistaken as such patients have little to gain and may have much to lose. ${ }^{8}$ At least in some circumstances, novel treatments can only be tried on extremely sick patients first. Indeed, the ethical calculus is potentially inverted: patients like Charlie arguably have everything to gain and nothing to lose.

There are three potential lessons here. First, that there should be a low threshold for allowing 
Charlie Gard was born at full term, apparently healthy, in August 2016. At a few weeks of age his parents noticed early signs of muscle weakness. At 2 months of age, he was admitted to Great Ormond Street Hospital (GOSH) with poor feeding, failure to thrive and respiratory failure. He was admitted to intensive care, where investigations led to the diagnosis of a rare severe mitochondrial disorder - infantile onset encephalomyopathic mitochondrial DNA depletion syndrome (MDDS).

The specific genetic form of MDDS in Charlie Gard (RRM2B) had previously been reported in approximately 15 infants, with typical clinical features including early onset, rapid progression and death in infancy. ${ }^{24}$ By that point, Charlie was paralysed and unable to breathe without respiratory support. He was found to have congenital deafness, and his heart, liver and kidneys were affected by the disorder. Doctors felt that Charlie's prognosis was extremely poor.

In early 2017, Charlie's parents identified an experimental treatment, previously used in a different form of MDDS, which they hoped might benefit Charlie. In mouse models of a myopathic form of MDDS (TK2), early supplementation with deoxypryrimidine nucleosides apparently bypasses the genetic defect and leads to a reduction in the biochemical defect and in the severity of the clinical phenotype. ${ }^{25}{ }^{26}$ Doctors at GOSH initially planned to use nucleoside treatment in Charlie, but in January he developed evidence of electrical seizures, and clinicians became convinced that treatment, both continued intensive care and the requested nucleoside therapy, would be futile. A US physician involved in the nucleoside research offered to provide treatment, and Charlie's parents raised funds for him to travel to the USA.

However, doctors at GOSH were not happy with Charlie being transferred overseas for treatment. They applied to the Family Division of the High Court on 28 February for permission to withdraw life support and to provide palliative care. Charlie's parents opposed this plan. On 11 April, Justice Francis ruled in favour of the hospital. Charlie's family appealed, and the decision was reviewed (and upheld) in the Court of Appeal (23 May), Supreme Court (8 June) and European Court of Human Rights (20 June). At that stage, all avenues of legal appeal had been exhausted, and plans were made to withdraw medical treatment.

Following widespread public and media attention, including statements of support by President Trump and Pope Francis, a number of international medical and scientific experts came forward offering treatment and presenting apparently new evidence of allegedly increased chance of benefit from nucleoside treatment. On 10 July, GOSH elected to bring this evidence back to the High Court. The court arranged for the US mitochondrial specialist to review Charlie in London. Following a multi-disciplinary meeting and new evidence of the severity of Charlie's illness including the results of a full body MRI, on 24 July his parents accepted that further treatment could not help him and withdrew their application to the court.

innovative therapies in patients who have exhausted all other conventional medical therapies and otherwise will die. Second, that experimental treatments should potentially be embarked upon without delay. ${ }^{9}$ In Charlie's case, it is ironic that delayed decision-making means that he could have received nucleoside treatment months ago, and by the time the case was finally concluded in court it would have been possible to assess if it had led to any improvement, or not. Third, there are of course limits to aggressively offering experimental treatment, particularly where the side effects of treatment may make it highly likely not to be in the individual's interests. Where the side effects are uncertain, it may be better to allow a time-limited trial of the therapy with a plan to actively withdraw treatment if side effects are significant or if there is no benefit after a suitable period.

\section{THE ROLE OF RESOURCES: WE NEED TO TALK ABOUT LIMITED RESOURCES}

Even if it were not harmful, treatment (whether experimental therapy or life support in intensive care) should not be provided if it is excessively costly and would mean denying other patients their slice of the limited healthcare pie. This issue of limited healthcare resources does not apply directly in the Gard case as Charlie's parents had raised funds independently for him to travel to the USA for treatment. ${ }^{12}$ It was not considered by the court. The Gard decision should not be seen therefore (contrary to the claims of some US politicians) as the decision of a single payer health system that is explicitly rationing treatment.

However, as noted by US paediatric intensivist Robert Truog, concern about finite health resources is legitimate even if parents or insurers pay for treatment. ${ }^{10}$ It is relevant even in the USA (and perhaps especially in the USA). ${ }^{11}$ Tertiary healthcare facilities, such as those that offered treatment to Charlie, are a result of community investment in medical research, medical education and medical care. The community has a stake in how those facilities are used, and in ensuring that they are used wisely (ie, with at least some plausible prospect of benefit). ${ }^{10}$

Furthermore, there is a deep resource-related paradox at the heart of this case, as in other cases of disputed, possibly futile treatment. While there is potential uncertainty about whether or not treatment would have been in Charlie's best interests, there is no uncertainty about resources. Continued intensive care in this case, in the face of a very low probability of improvement and high costs of treatment, represents an unreasonable and unfair use of limited healthcare resources. However, in an effort to adjudicate the difficult ethical question of the benefits and burdens of treatment for Charlie, treatment was prolonged at public expense for months. In that time, it is virtually certain that some children were denied transfer to the highly specialised intensive care unit at Great Ormond Street Hospital because of lack of capacity. It is virtually certain that in that time some elective (but vital) surgery was delayed. Because of concern for the well-being of other children needing the vital resource of the intensive care unit, it may have been better to allow the parents to take Charlie overseas months ago. Indeed, even if we accept that that would have been contrary to Charlie's best interests, it may have been a lesser harm overall.

However, resources have not been part of the central ethical debate for Charlie, and that is fundamentally because there is no clear process for clinicians to make resource-based decisions about provision of intensive care for patients. There is also no legal mechanism for courts to adjudicate on the issue of resources where there is a dispute.

\section{THE ROLE OF THE COURTS: WE NEED A FAIR, EXPEDIENT WAY OF RESOLVING DISPUTES}

Parents cannot have a final say in medical decisions for children, but nor can doctors. Just as in every other area of life, where there is a dispute that cannot be resolved between two parties 
Box 2 Some of the key factual and ethical questions arising from the Charlie Gard case

Factual questions

- What was Charlie's level of awareness/cognition?

- How much did he experience pain/suffer from intensive care?

- Can suffering from intensive care be alleviated completely/ partly by sedation/analgesia?

- What was the chance of improvement in Charlie's encephalopathy or myopathy?

- How long would treatment need to be provided to determine if he had any improvement?

- What is the best function that he could achieve with treatment?

- Could he be ventilator independent with treatment?

- How long could he live with continued life-sustaining treatment?

Ethical questions

What is the right thing to do?

- Would it be in Charlie's best interests to receive continued intensive care and nucleoside treatment?

- Would life for Charlie in his impaired state be a life worth living?

- Should we judge this based on subjective or objective accounts of well-being?

- In the best-case scenario (with maximum realistic improvement from nucleoside treatment), would his life be worth living?

- Should the interests of parents be taken into account?

- Should, and if so when should treatment be denied on the basis of limited public healthcare resources?

How should decisions be made?

- When should parents' requests for medical treatment be overruled?

- Should parents be permitted to consent to untested or extremely uncertain experimental treatment if a child would certainly die without it?

-What constitutes 'significant harm' to justify overruling parents?

- If parents are able to pay for treatment, should that change the permissibility of continuing/providing treatment?

- How should decisions about allocation of resources be made for individual patients?

- How should diverging views about medical facts be taken into account?

- Does it matter if those diverging views come from health professionals in different countries?

- How should diverging views about normative issues (eg, life worth living, parental rights) be taken into account?

- Should parents be free to take their child overseas for medical treatment unavailable in their home country?

- Should decisions be made through the courts, or in some extra-judicial process?

about an important issue, there needs to be a fair and impartial process for arbitration. In the UK, as in most other countries, the court serves that role. However, the court process is not perfect. It is adversarial, and can potentially make the ideal solution (agreement between parents and doctors) harder to achieve. It is costly. And it is potentially lengthy. In this case, the series of appeals has led to the worst of possible outcomes. Charlie Gard received months of intensive care that health professionals felt was contrary to his interests and doing more harm than good. But he did not receive the desired nucleoside treatment that his parents desired. Nobody has got the outcome that they wanted.

Is there an alternative? Because of the formidable epistemic and normative challenges in determining when treatment is futile, ${ }^{12}$ one solution in some jurisdictions has been to focus on developing a fair and legally supported due process for decision-making. ${ }^{1314}$ There are two key components to this process that could and arguably should be adopted in the UK for future disputes about treatment. The first is the establishment of a process of case review by an independent ethics review panel where physicians feel that continued treatment would be futile. That panel would be able to reach decisions about withholding or withdrawing treatment without the lengthy process of adjudicating and appealing evident in the Gard case. Importantly, we suggest that it would be important for such a panel to include ethical expertise and to consider (where relevant) inviting ethical experts as well as medical experts to inform decisions. It would require a wide range of clinical and scientific opinion to get the facts clear but also to make clear the level of uncertainty about the facts. The second is to allow families to secure desired treatment if they are able to identify alternative healthcare providers who are prepared and able to provide treatment. One limit to that may be the location of alternative providers.

\section{ETHICAL DECISIONS VERSUS CLINICAL DECISIONS: ALLOW AND SUPPORT REASONABLE DISAGREEMENT}

Much of the debate in the courtroom in the Gard case has been around medical evidence and factual claims, particularly about the reversibility of brain damage and the scientific plausibility of the experimental treatment (box 2). However, the decision in this case, and in other similar cases, is not a 'clinical decision'. It cannot be settled by questions of medical fact or scientific evidence alone.

Indeed, one of the striking (though not unique) features of this case is the presence of divergent expert testimony, and disagreement between key witnesses on whether treatment could help Charlie and whether it should be provided.

In court cases, one approach to witnesses who disagree about key facts is to assess the credibility of the witnesses and assign different weights to their testimony. Yet where the central question is value based and ethical, rather than scientific, consensus may be impossible. In those situations, dissensus may be just as important to note as consensus. ${ }^{15}$ Where there is reasonable disagreement between experts about medical treatment, we should usually allow patients (or their surrogates) to decide. In the Charlie Gard case, there was just such disagreement, with experts in New York and Rome initially willing to provide the requested treatment. That provided a powerful (though not irrefutable) argument in favour of allowing continued intensive care and nucleoside treatment. One vexed question is whether the disagreement in this case represented 'reasonable' disagreement. ${ }^{16}$ Those offering treatment need to be able to provide clear and coherent reasons for doing so, to demonstrate understanding of the specific clinical circumstances, and to demonstrate willingness to revise their view in the face of changing facts.

\section{MEDICAL TOURISM: ALLOW FAMILIES TO TRAVEL UNLESS ILLEGAL OR RISKS SIGNIFICANT HARM}

None of the medical experts in the UK who reviewed Charlie felt that the requested treatment would be in his best interests. However, experts in the USA and Italy offered to provide treatment. 
On the face of it, stopping patients from undertaking medical tourism appears to violate two important freedoms - the freedom to travel and the freedom to make decisions about medical treatment. There might be reasons for a country not to provide a particular treatment option, for example because it is unaffordable within a public healthcare system, or because doctors in that country do not approve of it, or lack experience or expertise in providing it, but usually patients should not be prevented from accessing treatment overseas.

However, particularly for children, there are a range of situations where it might be problematic for parents to travel to access controversial treatment. ${ }^{17}$ It is not acceptable for parents to bypass laws that are designed to protect children from harm by taking them out of the country (eg, to obtain female circumcision).

Where treatment options are contentious, but not illegal (and perhaps experimental treatment falls into this category), decisions to allow travel may need to be considered on a caseby-case basis. On the one hand, health professionals should arguably respect reasonable disagreement. On the other, they have a professional and legal duty to report cases if they suspect that parents' plans to take a child out of the country risk significant harm.

\section{CHALLENGING NORMATIVE AND CONCEPTUAL ISSUES: NEED FOR FURTHER ETHICAL ANALYSIS}

The central question about providing desired treatment or withdrawing and allowing Charlie to die is irreducibly normative. Because of that, it is important to be clear about some of the key value questions and concepts at stake. For example, in the initial court ruling, Judge Francis referred to Charlie's interest in maintaining his dignity, and the significance of allowing him to 'die with dignity'. Yet it was not clear what independent ethical role dignity played in the ethical evaluation of treatment. Dignity is a deeply contested concept in medical ethics. ${ }^{18} 19$ There were clearly different views between parents and professionals about whether it would be consistent with Charlie's dignity to continue intensive care.

Another fundamental issue is what counts as sufficient benefit to prolong life. The concept of a 'life worth living' is highly controversial, yet it remains at the heart of this case, and other cases. $^{2}$ For adults, it is possible to rely to a degree on subjective accounts of well-being, since adults can report on their experience of pain or pleasure. It is also possible (in at least some cases) to draw on their evaluations of what is or would be a sufficient benefit to provide life-prolonging treatment. However, for young children, and others who are not and have never been able to express their wishes or preferences, a subjective account is either meaningless or misleading. The alternative is an objective account of a life worth living that is robust and clear enough to be applied to contested cases, and also respects reasonable disagreement about value and values. That alternative remains to be established.

\section{REFLECTIVE EQUILIBRIUM, REASONS AND EVIDENCE: NEED FOR HUMILITY AND TRANSPARENCY}

How should value judgements be made? Philosopher John Rawls described a process of reflective equilibrium. This involves developing principles (such as the best interests principle and those of distributive justice) and concepts (such as well-being and a life worth living), but crucially revising these in line with intuitions about specific cases, such as Charlie's. This process is what judges engage in but judges, or doctors, are not necessarily or exclusively ethical experts.

Rawls described the qualities of people who should be engaged in reflective equilibrium. They should be knowledgeable about the relevant facts. Importantly, they should be 'reasonable': (1) being willing to use inductive logic, (2) being disposed to find reasons for and against a solution, (3) having an open mind, (4) making a conscientious effort to overcome their intellectual, emotional and moral prejudices. Lastly, they are to have 'sympathetic knowledge... of those human interests which, by conflicting in particular cases, give rise to the need to make a moral decision'. ${ }^{20}$

When a decision is arrived at, the decision together with its reasons and evidence needs to be made clear to those involved, and, in high-profile public cases, to the public at large.

In decisions about life support for a critically ill child, those who have to make the decision, whether they are parents, health professionals or high court judges, should aspire to the above qualities and engage in reflective equilibrium. However, perhaps the most distinctive feature of the Charlie Gard case is the way that this decision has been shared in real time with a massive national and international audience. Tens of thousands, perhaps hundreds of thousands, of people have been reading, thinking, and venturing opinions on the core questions and value judgements at stake.

Given the emotional and intellectual involvement of so many people in this profound and profoundly difficult decision, it is salient to remember Rawls' other key lesson about value judgements: participants in reflective equilibrium should display epistemic and normative humility, that is a calibrated confidence in their knowledge of empirical and moral truth.

As the sad case of Charlie Gard comes to a close, it is sobering but vital to step back from our own personal views on the case, and to remember that we can all get it wrong.

Contributors Both authors discussed the content of the article. JS produced an outline. DW refined and drafted the outline. Both edited and approved the final version.

Funding WT104848/Z/14/Z and WT106587/Z/14/Z

Competing interests None declared.

Provenance and peer review Not commissioned; internally peer reviewed.

(c) Article author(s) (or their employer(s) unless otherwise stated in the text of the article) 2018. All rights reserved. No commercial use is permitted unless otherwise expressly granted.

\section{REFERENCES}

1 Wilkinson D. Beyond resources: denying parental requests for futile treatment. Lancet 2017;389:1866-7

2 Savulescu J. Is it in Charlie Gard's best interest to die? Lancet 2017;389:1868-9.

3 Verhagen AA, de Vos M, Dorscheidt JH, et al. Conflicts about end-of-life decisions in NICUs in the Netherlands. Pediatrics 2009;124:e112-e119.

4 Nair T, Savulescu J, Everett J, et al. Settling for second best: when should doctors agree to parental demands for suboptimal medical treatment? J Med Ethics 2017;43:831-40.

5 Great Ormond Street Hospital for Children. Latest statement on Charlie Gard. 2017. http://www.gosh.nhs.uk/file/23611/download?token=aTPZchww

6 Wilkinson D. Burke, Briggs and Wills: why we should not fear the judgment in Charlie Gard: Practical Ethics blog. 2017. http://blog.practicalethics.ox.ac.uk/2017/07/burkebriggs-and-wills-why-we-should-not-fear-the-judgment-in-charlie-gard/

7 Wilkinson D, Savulescu J. Cost-equivalence and pluralism in publicly-funded healthcare systems. Health Care Anal. Published Online First: 6 Jan 2017. doi:10.1007/ s10728-016-0337-z.

8 Savulescu J. Harm, ethics committees and the gene therapy death. J Med Ethics 2001;27:148-50.

9 Savulescu J. The moral of the case of Charlie Gard: give dying patients experimental treatment ... early. Practical Ethics [blog], 5 Jul 2017. http://blog.practicalethics. ox.ac.uk/2017/07/the-moral-of-the-case-of-charlie-gard-give-dying-patientsexperimental-treatment-early/. 


\section{Charlie Gard}

10 Truog RD. The United Kingdom sets limits on experimental treatments: the case of Charlie Gard. JAMA 2017;318:1001-2.

11 Camosy C. Too expensive to treat? Finitude, tragedy and the neonatal ICU. Grand Rapids, Michigan: Eerdmans, 2010.

12 Wilkinson D. Futility. The International Encyclopedia of Ethics, 2017 [in press].

13 Stewart C. Futility determination as a process: problems with medical sovereignty, legal issues and the strengths and weakness of the procedural approach. J Bioeth Inq 2011;8:155-63.

14 Fine RL, Mayo TW. Resolution of futility by due process: early experience with the Texas Advance Directives Act. Ann Intern Med 2003;138:743-6.

15 Wilkinson D, Truog R, Savulescu J. In favour of medical dissensus: Why We should agree to disagree about end-of-life decisions. Bioethics 2016;30:109-18.

16 Wilkinson D, Savulescu J. Agreement and disagreement about experimental treatment: the Charlie Gard appeal: Practical Ethics blog. 2017. http://blog.practicalethics.ox.ac. uk/2017/05/agreement-and-disagreement-about-experimental-treatment-the-charliegard-appeal/

17 Wilkinson D. Medical tourism for controversial treatment options: Practical Ethics blog. 2017. http://blog.practicalethics.ox.ac.uk/2017/07/medical-tourism-forcontroversial-treatment-options/
18 Macklin R. Dignity is a useless concept. BMJ 2003;327:1419-20.

19 Killmister S. Dignity: not such a useless concept. J Med Ethics 2010:36:160-4.

20 Rawls J. Outline of a decision procedure for ethics. Philos Rev 1951;60:177-97.

21 Dyer C, Law DC. Law, ethics, and emotion: the Charlie Gard case. BMJ 2017;358:j3152.

22 Francis J. Decision and short reasons to be released to the media in the case of Charlie Gard: Judiciary of England and Wales. 2017. https://www.judiciary.gov.uk/ wp-content/uploads/2017/04/gard-press-summary-20170411.pdf (accessed 27 Apr 17).

23 Great Ormond Street Hospital -v- Yates and Gard: EWHC 1909 (Fam), 2017.

24 El-Hattab AW, Scaglia F. Mitochondrial DNA depletion syndromes: review and updates of genetic basis, manifestations, and therapeutic options. Neurotherapeutics 2013;10:186-98.

25 Garone C, Garcia-Diaz B, Emmanuele V, et al. Deoxypyrimidine monophosphate bypass therapy for thymidine kinase 2 deficiency. EMBO Mol Med 2014;6:1016-27.

26 Lopez-Gomez C, Levy RJ, Sanchez-Quintero MJ, et al. Deoxycytidine and deoxythymidine treatment for thymidine kinase 2 deficiency. Ann Neurol 2017;81:641-52. 